\title{
(2) OPEN ACCESS \\ Basic principles of neonatal bubble CPAP: effects on CPAP delivery and imposed work of breathing when altering the original design
}

\author{
Sonja Baldursdottir, ${ }^{1,2}$ Markus Falk, ${ }^{1,3}$ Snorri Donaldsson, ${ }^{1,2}$ Baldvin Jonsson, ${ }^{1,2}$ \\ Thomas Drevhammar (10)3
}

\begin{abstract}
- Additional material is published online only. To view, please visit the journal online (http://dx.doi.org/10.1136/ archdischild-2019-318073)

${ }^{1}$ Department of Women's and Children's Health, Karolinska Institutet, Stockholm, Sweden ${ }^{2}$ Department of Neonatology, Karolinska University Hospital, Stockholm, Sweden

${ }^{3}$ Department of Anesthesiology, Östersund Hospital, Östersund, Sweden
\end{abstract}

Correspondence to Dr Thomas Drevhammar Department of Anesthesiology, Östersund Hospital, 83183 Östersund, Sweden; thomas.drevhammar@ki.se

Received 12 August 2019 Revised 13 January 2020 Accepted 20 January 2020 Published Online First 11 February 2020

\begin{abstract}
Background The original bubble continuous positive airway pressure (bCPAP) design has wide-bore tubing and a low-resistance interface. This creates a stable airway pressure that is reflected by the submersion depth of the expiratory tubing. Several systems with alterations to the original bCPAP design are now available. Most of these are aimed for use in low-income and middleincome countries and have not been compared with the original design.
\end{abstract}

Objective We identified three major alterations to the original bCPAP design: (1) resistance of nasal interface, (2) volume of dead space and (3) diameter of expiratory tubing. Our aim was to study the effect of these alterations on CPAP delivery and work of breathing in a mechanical lung model. Dead space should always be avoided and was not further tested.

Methods The effect of nasal interface resistance and expiratory tubing diameter was evaluated with simulated breathing in a mechanical lung model without interface leakage. The main outcome was delivered CPAP and imposed work of breathing.

Results High-resistance interfaces and narrow expiratory tubing increased the work of breathing. Additionally, narrow expiratory tubing resulted in higher CPAP levels than indicated by the submersion depth. Conclusion Our study shows the significant effect on CPAP delivery and imposed work of breathing when using high-resistance interfaces and narrow expiratory tubing in bCPAP systems. New systems should include low-resistance interfaces and wide-bore tubing and be compared with the original bCPAP. Referring to all systems that bubble as bCPAP is misleading and potentially hazardous.

\section{INTRODUCTION}

Every year, an estimated 15 million babies are born preterm. ${ }^{1}$ Complications of preterm birth is the leading cause of neonatal mortality, and the WHO estimates that three out of four of these babies can be saved with improved maternal and neonatal care. The use of continuous positive airway pressure (CPAP) is one of the recommended interventions to reduce morbidity and mortality in preterm infants. $^{23}$

In 1971, Gregory et al introduced the first CPAP system intended for neonatal use. ${ }^{4}$ The distending pressure was created by a resistor clamp on the system expiratory limb. It had a water submersion pop-off pressure valve set at $30 \mathrm{cmH}_{2} \mathrm{O}$ and has

\section{What is already known on this topic?}

- In its original design with low-resistance interface and wide-bore expiratory tubing, the bubble continuous positive airway pressure (bCPAP) is pressure stable and easy to breathe through.

- In 2012, WHO noted that many devices were homemade or developed specifically for lowincome countries and needed to be tested for durability, reliability and safety.

- Alterations to the original bCPAP design include high-resistance interfaces, increased dead space and high-resistance expiratory tubing.

\section{What this study adds?}

- This study confirms the WHO concern about CPAP quality and safety by reviewing design alterations and testing them in a lung model.

- High-resistance interfaces and narrow expiratory tubing in bCPAP systems can significantly affect CPAP delivery and imposed work of breathing, potentially introducing the risk of CPAP failure or complications.

- It is important that new designs are described correctly and compared with the original bCPAP system.

therefore often been mistaken for a bubble continuous positive airway pressure (bCPAP) system. In the original bCPAP design, as described by Sahni and Wung, the resistor clamp was replaced with wide-bore expiratory tubing submersed in water, and the interface consisted of short binasal prongs connected directly to the tubing. ${ }^{5}$ This design made the system pressure stable and easy to breathe through.

The simplicity of bCPAP systems makes them ideal for use in low-income and middle-income countries. In the last 10 years, new devices with several alterations from the original design have been described. Examples are provided in table 1. Three design alterations of potential concern are increased interface resistance, increased system dead space and different diameters of expiratory tubing. These are summarised in figure 1 . 
Table 1 bCPAP design variations

\begin{tabular}{|c|c|c|c|c|}
\hline & $\begin{array}{l}\text { Interface } \\
\text { resistance }\end{array}$ & Dead space & $\begin{array}{l}\text { Expiratory tubing } \\
\text { resistance }\end{array}$ & Comment \\
\hline Sahni and Wung ${ }^{5}$ & Low & Low & Low & Used in several trials and manuscripts; Fisher \& Paykel bCPAP has a similar design \\
\hline Audu et $a l^{8}$ & High & Low & High & Description of modified oxygen cannula (figures 1-3) later used in clinical trial \\
\hline Brown et $a l^{31}$ & Low & High & Low $^{*}$ & Description of the first version of the Pumani CPAP (figure 1) \\
\hline Daga et a $l^{9}$ & High & Low & High & Clinical trial using modified oxygen cannula with seal (figures 1-5) \\
\hline Duket $^{10}$ & High & Low & High & $\begin{array}{l}\text { Review including modified oxygen cannula (figures } 2 \text { and 3). Other designs: original } \\
\text { bCPAP (figure 1) and high-resistance interface (RAM type, figure 5). }\end{array}$ \\
\hline Kawaza et a ${ }^{32}$ & Low & High & Low* & Clinical trial including Pumani first version, reference to Brown et al \\
\hline Chisti et alt $t^{11}$ & High & Low & High & Randomised trial including modified oxygen cannula, reference to Duke \\
\hline McAdams et al ${ }^{23}$ & High & Low & Unknown & $\begin{array}{l}\text { Case series and description of bCPAP with high-resistance interface (RAM type) } \\
\text { (figure 2) }\end{array}$ \\
\hline Ezenwa et $a l^{12}$ & High & Low & High & Retrospective observational study using modified oxygen cannula (figures 1 and 2) \\
\hline $\mathrm{WHO}{ }^{13}$ & High & Low & High & $\begin{array}{l}\text { Manual including modified oxygen cannula (figures } 15 \text { and 16). Other designs: } \\
\text { original CPAP (figure 14). }\end{array}$ \\
\hline Bennett et $a l^{33}$ & High & High & Low $^{*}$ & $\begin{array}{l}\text { Description of a bCPAP system with a high-resistance interface (RAM type) and } \\
\text { connector tube similar to Brown et al (figure 1) }\end{array}$ \\
\hline Falk et $\left.a\right|^{30}$ & Low & Low & High & Description of the second version of the Pumani CPAP (figure 2) \\
\hline Bjorklund et a/ ${ }^{39}$ & High & Low & High & Clinical trial using modified oxygen cannula with seal (figure 1) \\
\hline Thaddanee et $a l^{14}$ & High & Unknown & High & $\begin{array}{l}\text { Observational trial and description of two modified oxygen cannula systems } \\
\text { (figures } 1 \text { and 2). }\end{array}$ \\
\hline Amadi et al ${ }^{15}$ & High & Low & High & Observational trial and description of modified oxygen cannula systems (figure 1) \\
\hline
\end{tabular}

List of manuscripts with descriptions or use of bCPAP systems with design alterations from the original (top row). Dimensions are not always reported in manuscripts and some include several design variations. The figures or photographs refered to in the comment column can be found in the cited manuscripts.

${ }^{*}$ Data in the manuscript indicate that expiratory tubing resistance was not high.

†Properties refer to only one system in the manuscript. Details are provided in comment column.

bCPAP, bubble continuous positive airway pressure.

The design alterations listed previously suggest a wide variation in the design of systems referred to as bCPAP systems. The development of new systems has not been without concern: "Increasing use of CPAP without regulation is a concern. Many devices are in the "homemade" category; several low-cost bCPAP devices are being developed specifically for low-income countries but need to be tested for durability, reliability and safety'. ${ }^{6}$

Our aim was to study the effect of interface resistance and the internal diameter of the expiratory tubing on CPAP delivery and imposed work of breathing in a mechanical lung model. Large dead space in non-leakage settings is not safe and was therefore not further tested.

\section{METHODS}

Two important alterations to the original bCPAP design we identified, high-resistance interfaces and different diameters of expiratory tubing, were evaluated in a mechanical lung model.

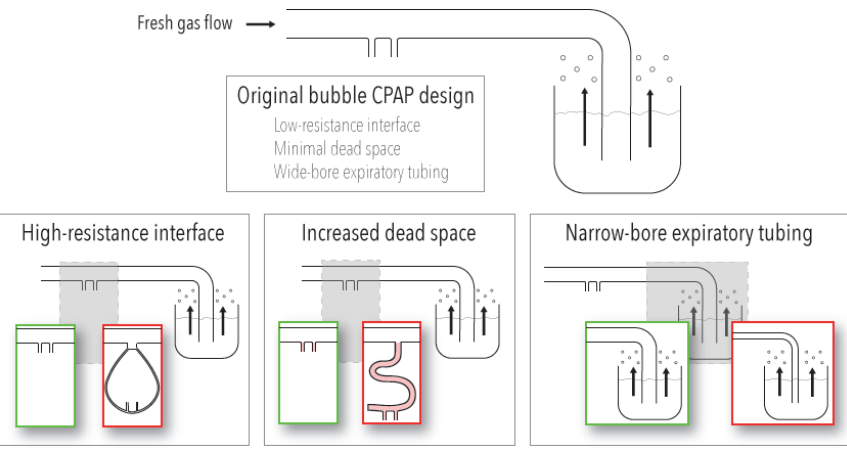

Figure 1 Summary of deviations from the original bubble CPAP system of clinical concern. Details on interface resistance, dead space and resistance of expiratory tubing presented in table 1.

\section{Mechanical lung model}

Measurements were performed using a mechanical lung model (ASL5000; Ingmar Medical, Pittsburgh, Pennsylvania, USA). Spontaneous breathing was simulated using a symmetrical, sinusoidal flow pattern with a flow maximum of $6 \mathrm{~L} / \mathrm{min}$ at a respiratory rate of 60 breaths $/ \mathrm{min}$. The main outcome was delivered $\mathrm{CPAP}$ and resistance to breathing. $\mathrm{CPAP}\left(\mathrm{cmH}_{2} \mathrm{O}\right)$ was measured as the average delivered pressure to the lung simulator. Resistance to breathing was measured as imposed work of breathing (mJ/breath).

Each interface was connected to the test lung without leakage. The driver flow was attached to the interface and the expiratory tubing was submersed in a large, open-top canister of water. The submersion depth was adjusted to $5 \mathrm{~cm}$ and tests were performed with non-humidified air at room temperature.

\section{Interface resistance}

To confirm the effect of interface resistance, three interfaces were tested. Two represent traditional bCPAP interfaces with short binasal prongs (Hudson prongs size 4 and Fisher \& Paykel 5040 prongs). As an example of a high-resistance interface, the RAM cannula (size Infant, orange) was included. ${ }^{7}$ The systems made from modified nasal oxygen cannulas (table $1^{8-15}$ ) generated too high pressures to be measured in our current setup (without leakage).

\section{Expiratory tubing}

To confirm the effects of changing the diameter of expiratory tubing, smooth tubing with a length of $1.5 \mathrm{~m}$ and internal diameters of 3, 4, 6, 8, 10 and $12 \mathrm{~mm}$ were tested. The tubing from Fisher \& Paykel was included as a reference $(1.47 \mathrm{~m}$ corrugated tubing, approximately $12 \mathrm{~mm}$ internal diameter). 


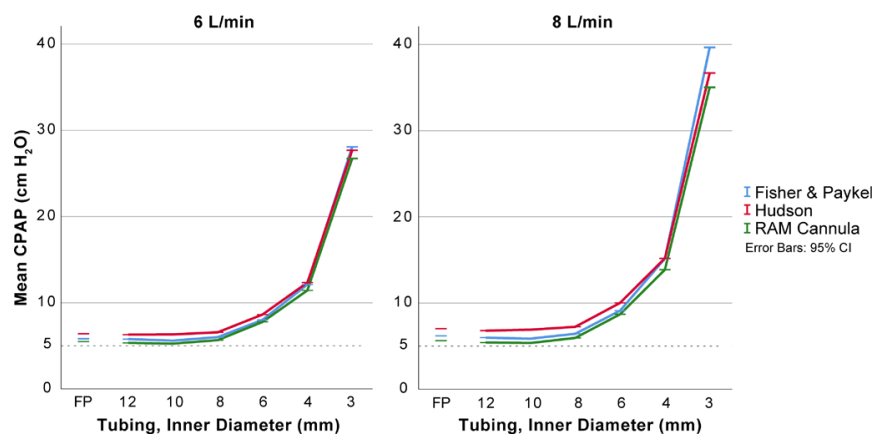

Figure 2 Effect of different interfaces and expiratory tubing diameters on mean CPAP. Mean CPAP for inner diameter expiratory tubing of 3-12 mm with three interfaces at $5 \mathrm{~cm}$ of submersion and with two levels of fresh gas flow. The Fisher \& Paykel original expiratory tubing was included to illustrate a commercially available alternative (corrugated tubing, $1.47 \mathrm{~m}$ length and approximately $12 \mathrm{~mm}$ internal diameter). Details and statistical comparisons are available as supplementary tables. CPAP, continuous positive airway pressure.

\section{Fresh gas flow}

All systems were tested with fresh gas flows of 6 and $8 \mathrm{~L} / \mathrm{min}$ calibrated with a Defender 510 (MesaLabs, California, USA) and adjusted with a standard air rotameter valve.

\section{Analysis}

Data were collected for at least 22 consecutive breaths and processed in the test lung software (Ingmar Medical) and exported to SPSS (version 25, IBM Corporation, Armonk, NY, USA). Mean values (95\% CIs) were calculated for breath numbers 2-20 and compared using unpaired t-tests or analysis of variance with Games-Howell post hoc testing. Statistical significance was set to $<0.05$.

\section{RESULTS}

The effects on mean CPAP and imposed work of breathing by the internal diameter of expiratory tubing, the interface resistance and the fresh gas flow are displayed in figures 2 and 3 with statistical analysis in data supplements.

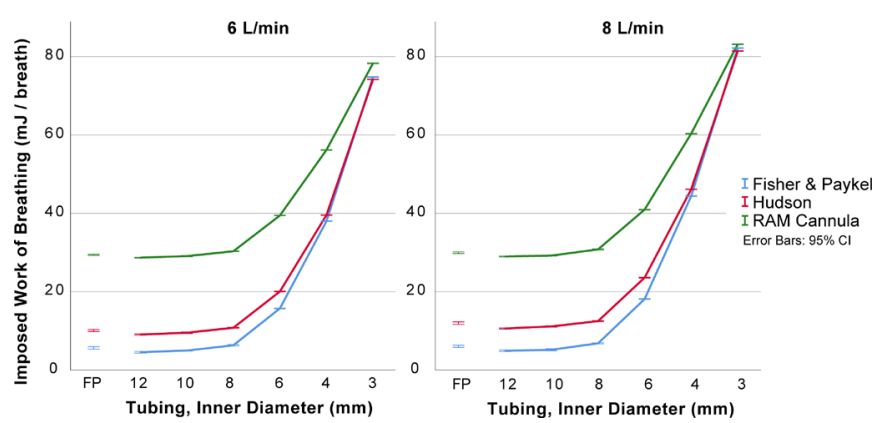

Figure 3 Effect of different interfaces and expiratory tubing diameters on mean imposed work of breathing. Resistance to breathing measured as imposed work of breathing ( $\mathrm{m} / /$ breath) for inner diameter expiratory tubing of 3-12 $\mathrm{mm}$ with three interfaces at $5 \mathrm{~cm}$ of submersion with two levels of fresh gas flow. The Fisher \& Paykel original expiratory tubing was included to illustrate a commercially available alternative (corrugated tubing, $1.47 \mathrm{~m}$ length and approximately $12 \mathrm{~mm}$ internal diameter). Details and statistical comparisons are available as supplementary tables.

\section{Interface resistance}

There were small absolute differences in delivered CPAP pressure for the different interfaces (Hudson, RAM and Fisher \& Paykel interfaces) and larger differences in imposed work of breathing between interfaces. The imposed work of breathing was highest for the RAM cannula and was most apparent with expiratory tubing with internal diameters less than $8 \mathrm{~mm}$. The data are presented in figures 2 and 3, with details in online supplementary tables $1-3$.

\section{Internal diameter of expiratory tubing}

With internal diameters less than $8 \mathrm{~mm}$, the delivered CPAP and imposed work of breathing were increased (figures 2 and 3, with details in online supplementary tables 1-3). The increase was non-linear. With expiratory tubing at least $8 \mathrm{~mm}$ in internal diameter, the absolute differences in delivered CPAP were small $\left(<1.5 \mathrm{cmH}_{2} \mathrm{O}\right.$ in all comparisons).

\section{Fresh gas flow}

The delivered CPAP and imposed work of breathing increased with increasing fresh gas flows in experiments with narrow expiratory tubing. This was less pronounced for expiratory tubing with internal diameters of at least $8 \mathrm{~mm}$ (figures 2 and 3 with details in online supplementary tables 1-3).

\section{DISCUSSION}

After the introduction of CPAP by Gregory et al, several clinical studies were conducted in the 1970s and 1980s using continuous distending pressure (CDP) for newborn infants with respiratory distress syndrome (RDS). ${ }^{4}$ As summarised by Bancalari and Sinclair, the use of CDP reduced mortality and improved oxygenation, while early application significantly reduced the need for mechanical ventilation and the total duration of respiratory assistance. ${ }^{16}$ The use of CPAP for the treatment of RDS was common initially, but with the increased resources available for treating very-low-birthweight infants with mechanical ventilation, the CPAP technique gradually fell into disuse. However, in a few centres, bCPAP and jet CPAP treatment remained the first choice for respiratory support for infants in respiratory distress. ${ }^{17-20}$ In recent times, a paradigm shift has occurred, and CPAP is now the evidence-based choice for initial treatment of infants with respiratory distress.

We refer to the original design and basic principles of bCPAP as a system with short binasal prongs, no dead space and widebore expiratory tubing. The origin of this system has not been published, but it has been used at Columbia University, New York, since the mid-1970s (JT Wung and R Sahni, personal communication 2019). These principles have also been applied in commercial systems for neonates such as the Fisher \& Paykel bCPAP system.

To meet the need for CPAP systems that can be used in lowresource settings, novel systems have been developed and are in clinical use. Although presented as bCPAP, many of these systems deviate from the basic principles of the original bCPAP design as presented in figure 1 and table 1. Our mechanical test lung simulations confirm that these alterations can have negative effects on performance.

\section{Interfaces}

Short binasal prongs or nasal masks are the recommended interface when providing CPAP to infants. ${ }^{21}{ }^{22}$ Several other interfaces are widely used for CPAP treatment. The RAM cannula interface has been used for providing CPAP and nasal intermittent 
positive pressure ventilation. ${ }^{23-26}$ This is not Food and Drug Administration approved, and the use is off-label. In our tests, the RAM cannula interface had a higher resistance to breathing than short binasal prongs. This is consistent with prior studies. Our results indicate that using a high-resistance interface like the RAM cannula, with a seal at the nares and closed mouth, might lead to an unintentionally high resistance to breathing.

Devices made from a modified standard oxygen cannula will have high resistance due to the narrow diameters. These were used in some trials included in table 1 but not included in our study as they generated pressures well above our equipment range when tested without leakage.

These designs combine a high-resistance interface with highresistance tubing and have characteristics that are probably closer to high-flow nasal cannula (HFNC) systems than the original bCPAP.

\section{Expiratory tubing}

The resistance of expiratory tubing adds pressure to the CPAP generated by the submersion depth. The resulting CPAP will be higher than intended, and this is not reflected by the submersion depth (figure 2). Our findings confirm results from previous studies. Mestriner et al investigated this in positive-expiratorypressure (PEP) therapy bottles for adults, ${ }^{27}$ and Wu et al recorded an increase in CPAP with increased expiratory limb resistance. ${ }^{28}$ The increased tubing resistance also leads to increased resistance to breathing (figure 3). This is expected and has been shown for other systems that generate CPAP using outflow resistance. ${ }^{29} 30$

With a $1.5 \mathrm{~m}$ expiratory tube, together with a fresh gas flow of $8 \mathrm{~L} / \mathrm{min}$ or less, the diameter needs to be at least $8 \mathrm{~mm}$ to avoid a higher CPAP level than intended.

\section{Dead space}

Although known for decades, the issue of dead space and risk of rebreathing is sometimes neglected when modifying the original bCPAP design. ${ }^{31-33}$ Without leakage, the use of long connecting tubing to an interface can lead to rebreathing and respiratory failure due to large dead space. At least two systems were identified that had neglected the issue of large dead space in their design. ${ }^{31-33}$

The risk of rebreathing with large dead space should always be considered when designing new bCPAP systems and should be avoided.

\section{Flow}

The driver flow for the original bCPAP design can be adjusted to compensate for leakage and peak inspiratory flows. ${ }^{34}$ For systems with high-resistance expiratory tubing, the increase in pressure above submersion depth will be more pronounced with higher driver flows (figure 2). For these systems and those using a high-resistance interface, recommendations on driver flows are difficult to give. Some systems have been observed to bubble even if no patient is connected. ${ }^{35} 36$

\section{High-flow nasal cannula}

HFNC has gained popularity as respiratory support in recent years because of its light weight and simplicity. The European RDS guidelines suggest that HFNC can be used during weaning as an alternative to CPAP. ${ }^{21}$ Both the HIPSTER trial and the HUNTER trial showed higher failure rates for HFNC compared with CPAP when used as primary respiratory support in preterm infants. ${ }^{37} 38$
CPAP systems in table 1 and designs in figure 1 with highresistance expiratory tubing and a high-resistance interface, such as the modified oxygen cannula systems, resemble HFNC systems more than the original bCPAP systems. With a very high delivered pressure, unrelated to submersion depth, and a highresistance interface, it is not likely that the infant can breathe through the device. Instead, the infant will be depending on leakage to avoid high resistance to breathing and excessive CPAP. These hybrid systems are not traditional CPAP systems nor dedicated HFNC systems. When used with a seal, they are potentially dangerous, equivalent to using an HFNC without assuring leakage.

We are not aware of any trials comparing these hybrid systems to the original bCPAP system. A trial by Chisti et al compared a modified oxygen cannula system, labelled as bCPAP, to low-flow and high-flow oxygen. ${ }^{11}$ The trial was stopped early because of higher clinical failure in the low-flow oxygen treatment group. It did not include an original bCPAP system. There is no evidence that the hybrid systems have a treatment effect equivalent to original bCPAP systems or commercial HFNC systems.

We recommend that bCPAP systems that apply the principles of the original design should be available as primary or rescue therapy for infants with more severe respiratory distress as they have a greater need for distending pressure to aid lung expansion. This could lead to less treatment failure and increased survival.

\section{Limitations}

The mechanical lung tests were designed to confirm and illustrate the effect of alterations from the basic principles of bCPAP. This means that not all systems, CPAP levels, tubing alternatives or flows were included. This article focused on design variations, and the risks of nasal trauma, humidification, gas supply, oscillations and costs were not discussed. The tests were performed without leakage. The very high CPAP pressures seen with narrow-bore expiratory tubing will result in leakage at the nose, through the mouth or to the gut.

\section{SUMMARY}

Our study shows significant effect on CPAP delivery and imposed work of breathing with changes in resistance of nasal interface and expiratory tubing. Narrow expiratory tubing resulted in higher CPAP levels than indicated by the submersion depth. Several of the systems referred to as bCPAP deviate from the original bCPAP principles, and some of the reviewed designs are better described as HFNC hybrids. New systems should be described correctly and compared with the original bCPAP.

The next logical step is to recognise these differences and to develop a strategy where the original bCPAP is used as primary treatment when available or as backup if simpler systems are failing. New systems should be introduced with caution and functionally defined as high-flow, hybrid or original bCPAP systems. Referring to all systems that bubble as bCPAP is misleading and potentially hazardous. Trials confirming the effectiveness and safety of new systems should be encouraged, and the original system should be used as the gold standard in such trials.

Acknowledgements Linnea Kristiansson worked with parts of the manuscript as her medical student research thesis.

Contributors All authors (SB, MF, SD, BJ and TD) had full access and were active in writing and reviewing the manuscript. Data collection and analysis were mainly performed by MF.

Funding The research was funded by the Swedish government and independent research funds. 
Competing interests None declared.

Patient consent for publication Not required.

Ethics approval The trial did not involve humans and no ethical review was needed.

Provenance and peer review Not commissioned; externally peer reviewed. Data availability statement All data are available from the authors on request.

Open access This is an open access article distributed in accordance with the Creative Commons Attribution Non Commercial (CC BY-NC 4.0) license, which permits others to distribute, remix, adapt, build upon this work non-commercially, and license their derivative works on different terms, provided the original work is properly cited, appropriate credit is given, any changes made indicated, and the use is non-commercial. See: http://creativecommons.org/licenses/by-nc/4.0/.

ORCID iD

Thomas Drevhammar http://orcid.org/0000-0002-4038-2221

\section{REFERENCES}

1 Chawanpaiboon S, Vogel JP, Moller A-B, et al. Global, regional, and national estimates of levels of preterm birth in 2014: a systematic review and modelling analysis. Lancet Glob Health 2019;7:e37-46.

2 Vogel JP, Oladapo OT, Manu A, et al. New who recommendations to improve the outcomes of preterm birth. Lancet Glob Health 2015;3:e589-90.

3 World Health Organization. Who recommendations on interventions to improve preterm birth outcomes. Geneva: World Health Organization, 2015.

4 Gregory GA, Kitterman JA, Phibbs RH, et al. Treatment of the idiopathic respiratorydistress syndrome with continuous positive airway pressure. $N$ Engl J Med 1971:284:1333-40

5 Sahni R, Wung J-T. Continuous positive airway pressure (CPAP). Indian J Pediatr 1998:65:265-71.

6 Howson C, Kinney M, Lawn J, et al. PMNCH, save the children, who. born too soon: the global action report on preterm birth. Geneva: World Health Organization, 2012.

7 Green EA, Dawson JA, Davis PG, et al. Assessment of resistance of nasal continuous positive airway pressure interfaces. Arch Dis Child Fetal Neonatal Ed 2019:104:F535-9.

8 Audu LI, Otuneye AT, Mukhtar MY, et al. Customized bubble continuous positive airway pressure (BCPAP) device at the National Hospital Abuja for the treatment of respiratory distress syndrome (RDS). Niger J Paed 2013;40:275-7.

9 Daga S, Mhatre S, Borhade A, et al. Home-Made continuous positive airways pressure device may reduce mortality in neonates with respiratory distress in low-resource setting. J Trop Pediatr 2014;60:343-7.

10 Duke T. Cpap: a guide for clinicians in developing countries. Paediatr Int Child Health 2014:34:3-11.

11 Chisti MJ, Salam MA, Smith JH, et al. Bubble continuous positive airway pressure for children with severe pneumonia and hypoxaemia in Bangladesh: an open, randomised controlled trial. Lancet 2015;386:1057-65.

12 Ezenwa B, Akintan P, Fajolu I, et al. Bubble CPAP in the management of respiratory distress syndrome in resource constrained settings: the LUTH experience. Pediatric Oncall 2016;13:9-12.

13 World Health Organization. Oxygen therapy for children: a manual for health workers. Geneva: World Health Organization, 2016.

14 Thaddanee $\mathrm{R}$, Chaudhari $\mathrm{A}$, Chauhan $\mathrm{H}$, et al. Bubble continuous positive airway pressure machine versus Indigenous bubble continuous positive airway pressure as a respiratory support in preterm babies with respiratory distress syndrome: a prospective outcome research at a tertiary care centre in Gujarat, India. Int I Contemp Pediatr 2018:5:493-8.

15 Amadi HO, Okonkwo IR, Abioye IO, et al. A new low-cost commercial bubble CPAP (bCPAP) machine compared with a traditional bCPAP device in Nigeria. Paediatr Int Child Health 2019;39:184-92.

16 Bancalari E, Sinclair J. Mechanical ventilation. In: Sinclair J, Bracken M, eds. Effective care of the newborn infant. Oxford: Oxford University Press, 1992: 200-20.
17 Avery ME, Tooley WH, Keller JB, et al. Is chronic lung disease in low birth weight infants preventable? A survey of eight centers. Pediatrics 1987;79:26-30.

18 Van Marter LJ, Allred EN, Pagano M, et al. Do clinical markers of barotrauma and oxygen toxicity explain interhospital variation in rates of chronic lung disease? the neonatology Committee for the developmental network. Pediatrics 2000;105:1194-201.

19 Kamper J, Wulff K, Larsen C, et al. Early treatment with nasal continuous positive airway pressure in very low-birth-weight infants. Acta Paediatr 1993:82:193-7.

20 Jónsson B, Katz-Salamon M, Faxelius G, et al. Neonatal care of very-low-birthweight infants in special-care units and neonatal intensive-care units in Stockholm. early nasal continuous positive airway pressure versus mechanical ventilation: gains and losses. Acta Paediatr 1997:86:4-10.

21 Sweet DG, Carnielli V, Greisen G, et al. European consensus guidelines on the management of respiratory distress syndrome -2019 update. Neonatology 2019:115:432-50.

22 King BC, Gandhi BB, Jackson A, et al. Mask versus prongs for nasal continuous positive airway pressure in preterm infants: a systematic review and meta-analysis. Neonatology 2019;116:100-14.

23 McAdams RM, Hedstrom AB, DiBlasi RM, et al. Implementation of bubble CPAP in a rural Ugandan neonatal ICU. Respir Care 2015;60:437-45.

24 Drescher GS, Hughes CW. Comparison of interfaces for the delivery of noninvasive respiratory support to low birthweight infants. Respir Care 2018;63:1197-206.

25 Petrillo F, Valenzano L, Franco C, et al. Pulmonary Recruitment Strategy in Preterm Neonates $<29$ Weeks of Gestational Age to Reduce the Need for Intubation in the Delivery Room. Am J Perinatol 2019;36:S115-9.

26 Singh N, McNally MJ, Darnall RA. Does the ram cannula provide continuous positive airway pressure as effectively as the Hudson prongs in preterm neonates? Am J Perinatol 2019:36:849-54.

27 Mestriner RG, Fernandes RO, Steffen LC, et al. Optimum design parameters for a therapist-constructed positive-expiratory-pressure therapy bottle device. Respir Care 2009;54:504-8.

28 Wu C-S, Lee C-M, Yuh Y-S, et al. Influence of changing the diameter of the bubble generator bottle and expiratory limb on bubble CPAP: an in vitro study. Pediatr Neonatol 2012;53:359-65.

29 Falk M, Donaldsson S, Jonsson B, et al. Return of neonatal CPAP resistance - the Medijet device family examined using in vitro flow simulations. Acta Paediatr 2017:106:1760-6.

30 Falk M, Donaldsson S, Drevhammar T. Infant CPAP for low-income countries: an experimental comparison of standard bubble CPAP and the Pumani system. PLoS One 2018;13:e0196683.

31 Brown J, Machen H, Kawaza K, et al. A high-value, low-cost bubble continuous positive airway pressure system for low-resource settings: technical assessment and initial case reports. PLoS One 2013;8:e53622.

32 Kawaza K, Machen HE, Brown J, et al. Efficacy of a low-cost bubble CPAP system in treatment of respiratory distress in a neonatal ward in Malawi. PLoS One 2014:9:e86327.

33 Bennett DJ, Carroll RW, Kacmarek RM. Evaluation of a low-cost bubble CPAP system designed for resource-limited settings. Respir Care 2018:63:395-403.

34 Sahni R, Schiaratura M, Polin RA. Strategies for the prevention of continuous positive airway pressure failure. Semin Fetal Neonatal Med 2016;21:196-203.

35 Claassen CC, Hillman NH, Brown K, et al. Comparison of bubble CPAP devices using ram cannula for extubation failure in very low birth weight infants: randomized and cohort studies. Neonatology 2019:115:28-35.

36 Won A, Suarez-Rebling D, Baker AL, et al. Bubble CPAP devices for infants and children in resource-limited settings: review of the literature. Paediatr Int Child Health 2019;39:168-76

37 Roberts CT, Owen LS, Manley BJ, et al. Nasal high-flow therapy for primary respiratory support in preterm infants. N Engl J Med 2016;375:1142-51.

38 Manley BJ, Arnolda GRB, Wright IMR, et al. Nasal high-flow therapy for newborn infants in special care nurseries. N Engl J Med 2019;380:2031-40.

39 Bjorklund AR, Odongkara Mpora B, Steiner ME, et al. Use of a modified bubble continuous positive airway pressure (bCPAP) device for children in respiratory distress in low- and middle-income countries: a safety study. Paediatr Int Child Health 2019:39:160-7. 